\title{
Modified Green Tea Polyphenols, EGCG-S and LTP, Inhibit Endospore in Three Bacillus spp.
}

\author{
Bushra Ali ${ }^{1}$, Lee H. Lee ${ }^{1}$, Nozrin Laskar1, Nadia Shaikh', Hassan Tahir ${ }^{1}$, Stephen D. Hsu², \\ Robert Newby Jr. ${ }^{3}$, Jonathan Valsechi-Diaz ${ }^{3}$, Tinchun Chu $^{3^{*}}$ \\ ${ }^{1}$ Department of Biology, Montclair State University, Montclair, NJ, USA \\ ${ }^{2}$ Department of Oral Biology, Augusta University, Augusta, GA, USA \\ ${ }^{3}$ Department of Biological Sciences, Seton Hall University, South Orange, NJ, USA \\ Email: *tin-chun.chu@shu.edu
}

How to cite this paper: Ali, B., Lee, L.H., Laskar, N., Shaikh, N., Tahir, H., Hsu, S.D., Newby Jr., R., Valsechi-Diaz, J. and Chu, T. (2017) Modified Green Tea Polyphenols, EGCG-S and LTP, Inhibit Endospore in Three Bacillus spp. Advances in Microbio$\log , 7,175-187$.

https://doi.org/10.4236/aim.2017.73014

Received: February 3, 2017

Accepted: March 6, 2017

Published: March 9, 2017

Copyright ( 2017 by authors and Scientific Research Publishing Inc. This work is licensed under the Creative Commons Attribution International License (CC BY 4.0).

http://creativecommons.org/licenses/by/4.0/

\begin{abstract}
Endospores have the ability to withstand extreme temperature, desiccation, ultraviolet radiation and chemicals which make them a threat to the food and healthcare industry. Green tea polyphenols (GTP), contain anti-microbial and anti-spore properties but not stable. In this study, two modified lipophilic green tea polyphenols, epigallocatechin-3-gallate-sterate (EGCG-S) and crude lipophilic green tea polyphenols (LTP), were used to compare their anti-spore effect with EGCG and crude GTP. Purified endospores from Bacillus cereus (B. cereus), B. megaterium and B. subtilis were treated with $1 \%$ or $5 \%$ of four tea polyphenols. Log reduction showed colony forming units (CFU) reduced significantly in all treated samples, ranging from 1.27 to 4.31 with no survivals $(\mathrm{CFU}=0)$ in four samples $(P<0.05)$. Average percentage of inhibition for these polyphenols treatment ranged from $91.68 \%$ to $100 \%$. The EGCG-S and LTP have equal or better anti-spore activities compared with EGCG and GTP. EGCG-S and LTP were further used to carry out time course study on B. cereus. The results indicated that 15 min of treatment of $1 \%$ and 5\% LTP and EGCG-S are able to inhibit $98.7 \%$ to $100 \%$ of germination. Transmission and scanning electron microscopy studies showed that EGCG-S caused surface disruption and damaged spores structural integrity. EGCG-S and LTP are stable anti-spore agents may aid in preventing food and beverage spoilage caused by sporeforming bacteria as well as preventing contamination in the medical industry.
\end{abstract}

\section{Keywords}

Bacterial Spores, Antimicrobials, Bacillus, Germination, Biocontrol

\section{Introduction}

Endospores are considered the most resistant living structures known because of 
their high degree of resistance to heat, chemicals and ultraviolet (UV) radiation [1] [2] [3]. Bacillus spp. are endospore formers that can cause numerous foodborne diseases and food poisoning [4] [5]. Not all bacterial endospores are eliminated during general food processing, thus they have remained a huge problem within the food industry for decades.

The process of endospore formation requires initiative signals from the environment, metabolism, and the cell cycle of the bacteria to ensure that sporulation occurs only in non-favorable conditions [6]. Sporulation begins with autophosphorylation of one of the five sensor kinases, followed by the phosphorelay pathway initiation [7]. This dormant stage of Gram-positive bacteria allows the bacterial cells to survive for a prolonged period of time. When the conditions become favorable, endospores will reactivate and germinate into vegetative cells. Vegetative cells are able to produce toxin and cause food poisoning. Common spore-forming bacteria that can cause food poisoning are Clostridium botulinum (C. botulinum), Clostridium perfringens (C. perfringens), and Bacillus cereus (B. cereus). C. botulinum produces a neurotoxin, and is primarily found in smoked sausages, improper canning, and honey [8] [9]. C. perfringens is commonly found in the meat industry (meat and equipment), hospitals (medical devices), restaurants (utensils/furniture), and homes for the elderly. Whereas $B$. cereus is commonly found in the dairy industry, rice, spices, and dried foods, and is much more difficult to be controlled than C. perfringens [4]. B. cereus can contaminate milk and dairy products with very low infective dose of $10^{3}-10^{4}$ bacterial cells/g, the heating process in pasteurization is insufficient to eliminate all spores, the psychrotrophic nature of the spores allows them to thrive in cold environments, and the long appendages on the surface of the spores permits great adherence. Spores are capable of adhering to the big vessels, pipelines and tanks used in dairy industries, thus allowing them to persist during routine cleaning procedures [4] [10]. Treating these endospores is usually more difficult due to their properties of heat and antimicrobial chemical resistant [11].

Many studies suggest that epigallocatechin-3-gallate (EGCG), the most abundant green tea polyphenols (GTP) from leaves of the tea plant Camellia sinensis, can accumulate to concentrations up to $1 \mathrm{mg} \cdot \mathrm{mL}^{-1}$ in green tea [12] [13]. EGCG has been shown to have many pharmacological activities including anti-carcinogenic, antiviral, antibacterial and anti-inflammatory effects [14]-[24]. A major advantage of EGCG as a potential agent is that it is non-toxic, and can be consumed or applied topically without adverse effects [25]. The US Food and Drug Administration (FDA) has classified EGCG as a safe compound [18]. However, EGCG itself is unstable in aqueous solution and readily oxidizes, resulting in loss of activity [26] [27]. It has been proposed that fatty acid-modified polyphenols could be effective agents with the same activity as GTPs [26]. These lipid esters of EGCG have been prepared both enzymatically and chemically and are also referred to as lipid-soluble tea polyphenols (LTPs) [27]. LTPs could significantly improve formulations of consumer products by increasing the bioavailability of GTPs [26]. 
Green tea catechins have shown inhibitory effects on the vegetative growth of the spore forming bacteria like $C$. botulinum and B. cereus [28]. There are also reports indicating that EGCG can work on the heat resistant spores in B. stearothermophilus, C. thermoaceticum [29]. Hara-Kudo's group suggested that GTP is able to damage the spore membrane [28].

In this study, we tested the efficacy of modified lipophilic tea polyphenols EGCG-S and LTP, also compared their effect with EGCG and GTP. We used a combination of colony forming units (CFU) and time course analysis to determine the minimum time and inhibitory concentration; as well as electron microscopy analysis to elucidate the mechanism of tea polyphenols on spores germination.

\section{Materials and Methods}

\subsection{Bacterial Cultures}

Bacterial strains of Bacillus cereus (B. cereus) (Carolina Biological Supply Co., Item\# 154870A), Bacillus megaterium (B. megaterium) (Carolina Biological Supply Co., Item\# 154900A) and Bacillus subtilis (B. subtilis) (Carolina Biological Supply Co., Item\# 154921A) were grown in nutrient agar or nutrient broth aseptically. All stock cultures were maintained at $4^{\circ} \mathrm{C}$. The microorganisms were grown overnight at $37^{\circ} \mathrm{C}$ from the stock cultures prior to every experiment in an incubator shaker at $250 \mathrm{rpm}$. Throughout the study, each microorganism was constantly maintained and tested for purity prior to carrying out each experiment.

\subsection{Endospore Enrichment and Purification}

B. cereus, B. megaterium and B. subtilis were incubated on modified nutrient agar plates (supplemented with $0.06 \mathrm{~g}$ of $\mathrm{MgSO}_{4}$ and $0.25 \mathrm{~g}$ of $\mathrm{KH}_{2} \mathrm{PO}_{4}$ per liter) respectively at $37^{\circ} \mathrm{C}$ for 10 days to enhance endospore formation [30]. After 10 days, Schaeffer Fulton differential stain was conducted to observe the endospore and vegetative cells [31]. The endospores were then purified by centrifugation at room temperature for $10 \mathrm{~min}$ at $8100 \mathrm{x} \mathrm{g}$. The supernatant was discarded and the endospores were suspended in sterile deionized water and vortexed to create a homogenous suspension. The suspension was heated for $20 \mathrm{~min}$ at $75^{\circ} \mathrm{C}$ to eliminate any remaining vegetative cells and obtain pure endospores. The green tea polyphenols EGCG, EGCG-Stearate (EGCG-S), GTP, and LTP with concentrations of $1 \%$ or $5 \%$ were added to the respective spore samples for $2 \mathrm{~h}$. A serial dilution of $10^{-2}, 10^{-3}$ and $10^{-4}$ was conducted. $100 \mu \mathrm{L}$ of each sample was then plated onto nutrient agar plates and incubated for $24 \mathrm{~h}$ at $37^{\circ} \mathrm{C}$. Colony forming units (CFU) were subsequently recorded.

\subsection{Green Tea Polyphenols Preparation}

All four green tea polyphenols, EGCG, EGCG-S, GTP, and LTP were purchased from Camellix LLC, Augusta, GA. Both GTP and EGCG stock solutions (10\%) were prepared in sterile deionized water freshly before use. The solution was 
then vortexed for $1-2 \mathrm{~min}$ at maximum speed to allow all contents to completely dissolve. Both LTP and EGCG-S stock solution (10\%) were prepared using $100 \%$ ethanol.

\subsection{Colony Forming Unit (CFU) Assay}

Purified endospores from B. cereus, B. megaterium and B. subtilis were treated for $2 \mathrm{~h}$ with $1 \%$ or $5 \%$ of tea polyphenols (EGCG, EGCG-S, GTP, and LTP) respectively. The samples were then serially diluted, plated onto nutrient agar plates, and subsequently incubated at $37^{\circ} \mathrm{C}$ for $24 \mathrm{~h}$. After incubation, the colony forming unit (CFU) was obtained. The non-treated samples were used as control. Three repeating experiments were carried out and the mean and standard deviation of the results were obtained. The log reduction and the percentage of inhibition were calculated with Equations ((1) and (2)), respectively.

$$
\begin{gathered}
\text { Log reduction }=\log _{10}\left(\frac{\text { CFU control }}{\text { CFU treated }}\right) \\
\% \text { inhibition }=\frac{(\text { CFU control }- \text { CFU treated })}{\text { CFU control }} \times 100 \%
\end{gathered}
$$

\subsection{Time Course Study}

For this study, B. cereus was used and the protocols were the same as previously described. In order to determine the minimum time needed to inhibit the spore germination, a time course experiment was carried out. Instead of treating the spores with tea polyphenols for $2 \mathrm{~h}$, the endospores were treated for 5, 10, 15, and 30 min with $1 \%$ and $5 \%$ of tea polyphenols EGCG-S or LTP. The samples were then serially diluted, plated, and incubated as previously described. The CFU was obtained from each treatment time point. Untreated samples were used as controls. Triplicates were carried out; the mean, standard deviation (SD), and the percentage of germinated cells were determined by using Equation (3).

$$
\% \text { germinated cells }=\frac{\mathrm{CFU} \text { treated }}{\mathrm{CFU} \text { control }} \times 100 \%
$$

\subsection{Transmission and Scanning Electron Microscopy}

The endospores were prepared and treated with 1\% EGCG-S for $2 \mathrm{~h}$, samples were resuspended in 5\% glutaraldehyde for $1 \mathrm{~h}$ to process the primary fixation. The spores were pelleted down by centrifuging at $16,000 \times g$ and then resuspended in $50 \mu \mathrm{L}$ of $4 \%$ sodium cacodylate agarose. The samples were prepared for transmission electron microscopy (TEM) according to a previously published method [32].

As for scanning electron microscopy (SEM), the endospores were prepared and treated with $1 \%$ EGCG-S for $2 \mathrm{~h}$, placed onto $0.45 \mu \mathrm{m}$ filter. Samples were rinsed with PBS ( $\mathrm{pH} 7.2$ ) or $0.1 \mathrm{~mol} \cdot \mathrm{l}^{-1}$ sodium cacodylate buffer $\left[\mathrm{Na}\left(\mathrm{CH}_{3}\right)_{2} \mathrm{AsO}_{2} \cdot 3 \mathrm{H}_{2} \mathrm{O}\right]$ three times for 5 min each; fixed with $2.5 \%$ glutaraldehyde in $0.1 \mathrm{~mol} \cdot \mathrm{l}^{-1}$ cacodylate buffer for $30 \mathrm{~min}$ at room temperature. The sam- 
ples were further fixed, went through a series of dehydration and were immersed in ethanol [33], followed by drying with liquid $\mathrm{CO}_{2}$ at $1072 \mathrm{psi}$ and $31^{\circ} \mathrm{C}$ in Denton Critical Point Dryer. Samples were mounted on a stub and coated with a thin layer of copper metal film using Denton IV Sputter Coater. Images were captured with a Hitachi S-3400N Scanning Electron Microscope.

\subsection{Statistical Analysis}

All experiments were carried out in triplicates and one way analysis of variance (ANOVA) was conducted with SPSS. $P<0.05$ is considered as statistically significant.

\section{Results}

\subsection{Lipophilic Green Tea Polyphenols, EGCG-S and LTP, Are Able to Inhibit Endospore Germination Equally Well or Better than Hydrophilic Green Tea Polyphenols, EGCG and GTP in Three Bacillus spp.}

Purified endospores from B. cereus, B. megaterium and B. subtilis were treated with four types of green tea polyphenols: hydrophilic green tea polyphenols GTP, EGCG and lipophilic green tea polyphenols LTP and EGCG-S. Mean, standard deviation (SD) of the colony forming unit (CFU) and log reduction were calculated and presented in bar graphs (Figures 1-3). Log reduction showed CFU reduced significantly in all treated samples, ranging from 1.27 to 4.31 with no survivals $(\mathrm{CFU}=0)$ in four samples $(P<0.05)$ (Table 1$)$. Percentage of inhibition was also calculated based on CFU reduction. For B. cereus, the percentage of inhibition of $1 \%$ and 5\% EGCG-S treatment were $98.28 \% \pm 1.22 \%$ and $99.63 \% \pm 0.06 \%$ respectively; $1 \%$ and $5 \%$ LTP treatment were $100 \% \pm 0 \%$

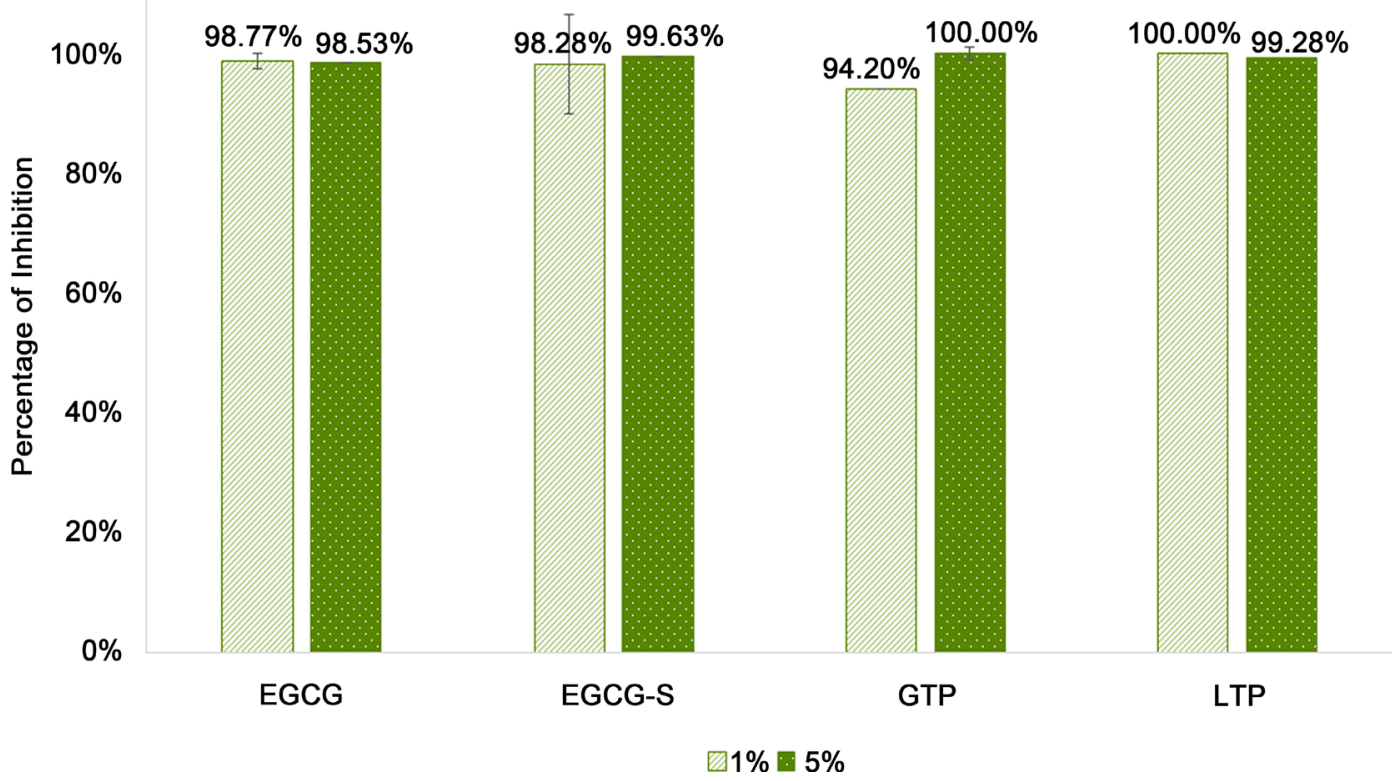

Figure 1. Percentage of inhibition of 1\% (light green), 5\% (dark green) of EGCG, EGCG-S, GTP and LTP treatment on the CFU of $B$. cereus endospore germination. 


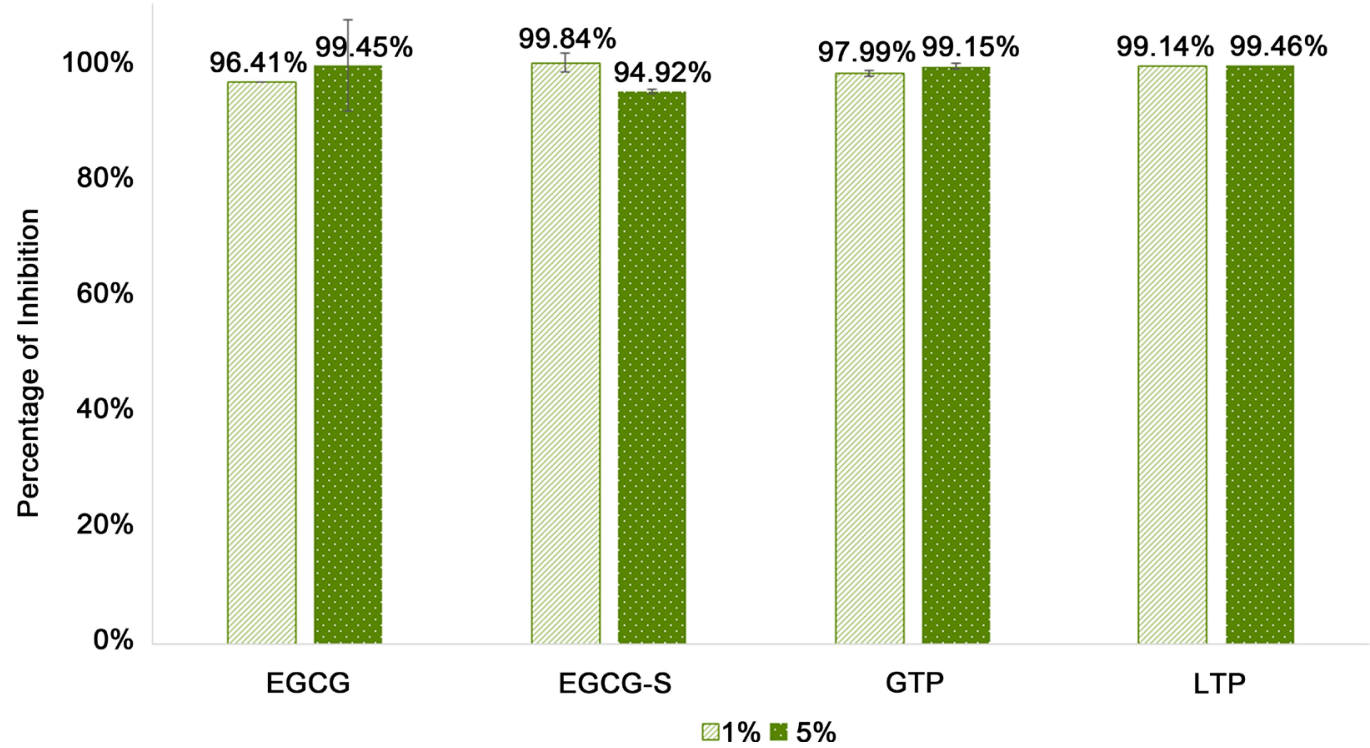

Figure 2. Percentage of inhibition of 1\% (light green), 5\% (dark green) of EGCG, EGCG-S, GTP and LTP treatment on the CFU of $B$. megaterium endospore germination.

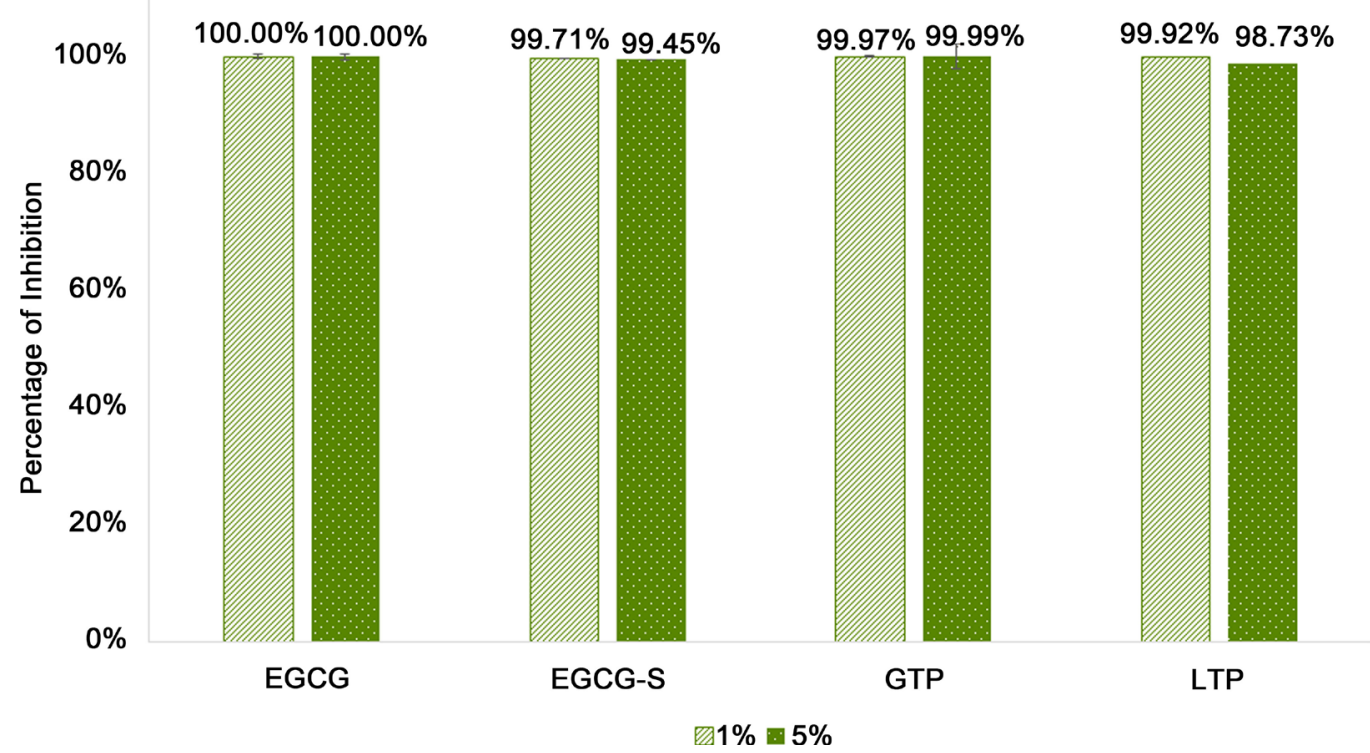

Figure 3. Percentage of inhibition of $1 \%$ (light green), 5\% (dark green) of EGCG, EGCG-S, GTP and LTP treatment on the CFU of $B$. subtilis endospore germination.

and $99.28 \% \pm 1.02 \%$ respectively; $1 \%$ and $5 \%$ EGCG treatment were $98.77 \% \pm$ $0.54 \%$ and $98.53 \% \pm 0.92 \%$ respectively; $1 \%$ and $5 \%$ GTP treatment were $94.20 \%$ $\pm 8.20 \%$ and $100 \% \pm 0 \%$ respectively (Figure 1 ). For B. megaterium, the percentage of inhibition of $1 \%$ and $5 \%$ EGCG-S treatment were $99.84 \% \pm 0.02 \%$ and $94.92 \% \pm 7.86 \%$ respectively; $1 \%$ and $5 \%$ LTP treatment were $99.15 \% \pm 0.58 \%$ and $99.46 \% \pm 0.52 \%$ respectively; $1 \%$ and $5 \%$ EGCG treatment were $96.41 \% \pm$ $4.19 \%$ and $99.45 \% \pm 0.46 \%$ respectively; $1 \%$ and $5 \%$ GTP treatment were $97.99 \%$ $\pm 1.54 \%$ and $99.15 \% \pm 0.34 \%$ respectively (Figure 2 ). For $B$. subtilis, the percentage of inhibition of $1 \%$ and $5 \%$ EGCG-S treatment were $99.71 \% \pm 0.41 \%$ and $99.45 \% \pm 0.51 \%$ respectively; $\%$ and $5 \%$ LTP treatment were $99.92 \% \pm 0.15 \%$ and 
Table 1. Colony forming unit (CFU) and log reduction of $1 \%$ and $5 \%$ of EGCG, EGCG-S, GTP and LTP treated verse control samples on endospore germination in B. cereus, B. megaterium and B. subtilis.

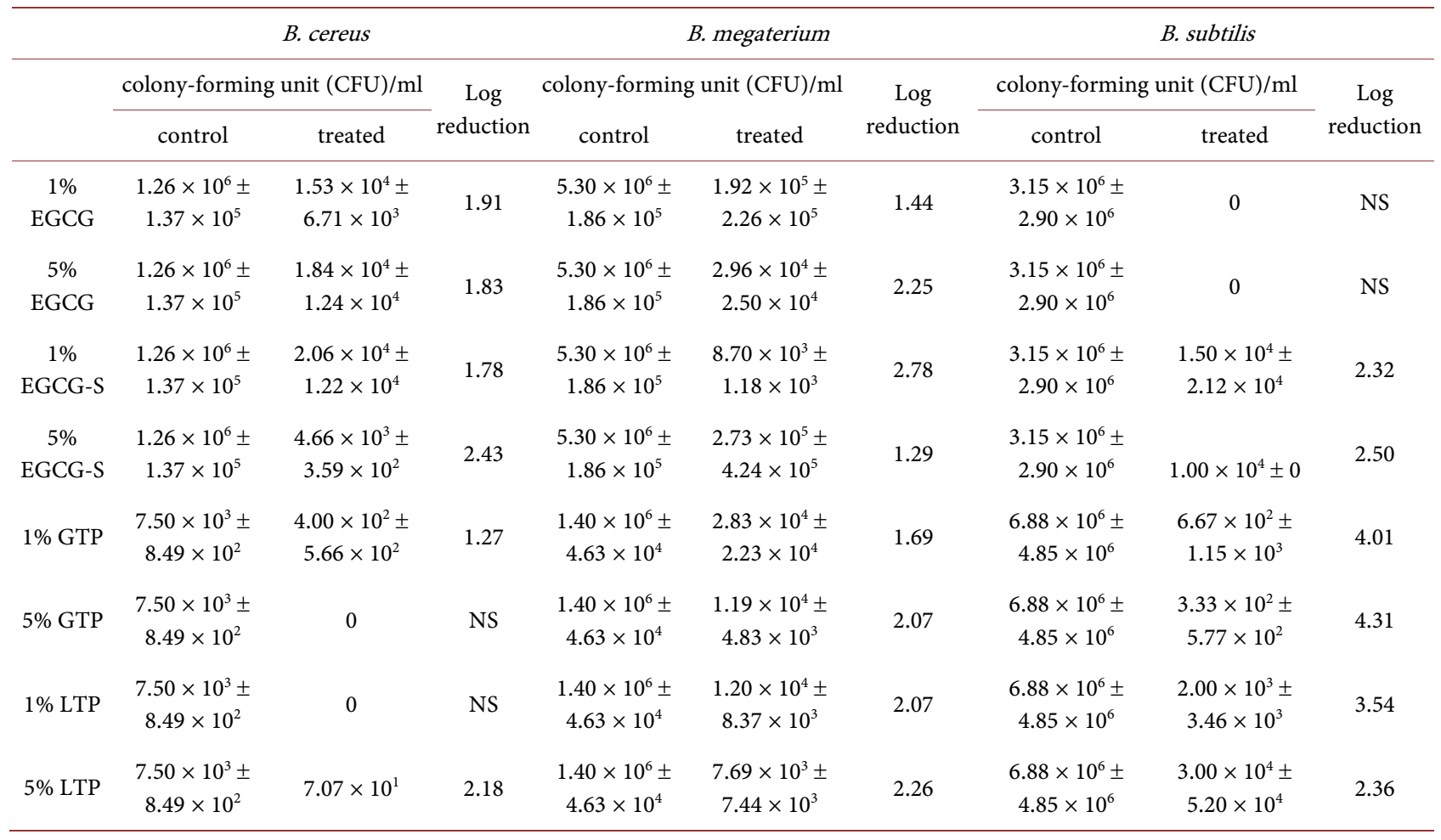

NS: no survival

$98.73 \% \pm 2.20 \%$ respectively; $1 \%$ and $5 \%$ EGCG treatments were both $100 \% \pm$ $0 \% ; 1 \%$ and $5 \%$ GTP treatment were $99.97 \% \pm 0.05 \%$ and $99.99 \% \pm 0.02 \%$ respectively (Figure 3 ). The results indicated that the anti-spore activity of $1 \%$ and 5\% of EGCG-S and LTP are equal or better in comparing with EGCG and GTP. All four types of tea polyphenols could significantly inhibit the germination of the endospores in three different Bacillus spp. post $2 \mathrm{~h}$ treatment. The percentage inhibition ranged from $94.21 \%$ to $100 \%$.

\subsection{A 15-min Treatment of 1\% EGCG-S or 1\% LTP Is Sufficient to Completely Inhibit Endospore Germination in B. cereus}

A time course study was performed by monitoring the cells with the treatment time of 5, 10, 15 and 30 mins to find the optimal treatment period. As shown in Figure 4, for 1\% EGCG-S, treatment for 5, 10, 15 and $30 \mathrm{~min}$, the percentage of viability were $19.11 \% \pm 0.019 \%, 12.61 \% \pm 0.035 \%, 0.40 \% \pm 0.004 \%$, and $0.27 \% \pm$ $0.005 \%$ respectively. For 5\% EGCG-S, treatment for 5, 10, 15 and $30 \mathrm{~min}$, the percentage of viability were $14.02 \% \pm 0.020 \%, 10.56 \% \pm 0.021 \%, 0 \% \pm 0 \%$, and $0 \% \pm 0 \%$ respectively; $1 \%$ LTP treatment for $5,10,15$ and $30 \mathrm{~min}$, the percentage of viability were $10.02 \% \pm 0.033 \%, 10.63 \% \pm 0.020 \%, 1.33 \% \pm 0.005 \%$, and $3.47 \%$ $\pm 0 \%$ respectively. For $5 \% \mathrm{LTP}$, treatment for $5,10,15$ and $30 \mathrm{~min}$, the percentage of viability were $7.92 \% \pm 0.021 \%, 7.32 \% \pm 0.051 \%, 0.13 \% \pm 0.002 \%$, and $0 \%$ $\pm 0 \%$ respectively. $1 \%$ EGCG-S for 5 to 30 min yielded an average percentage of inhibition ranging $80.98 \%-99.73 \%$ and 5\% EGCG-S for 5 to 30 min yielded a 


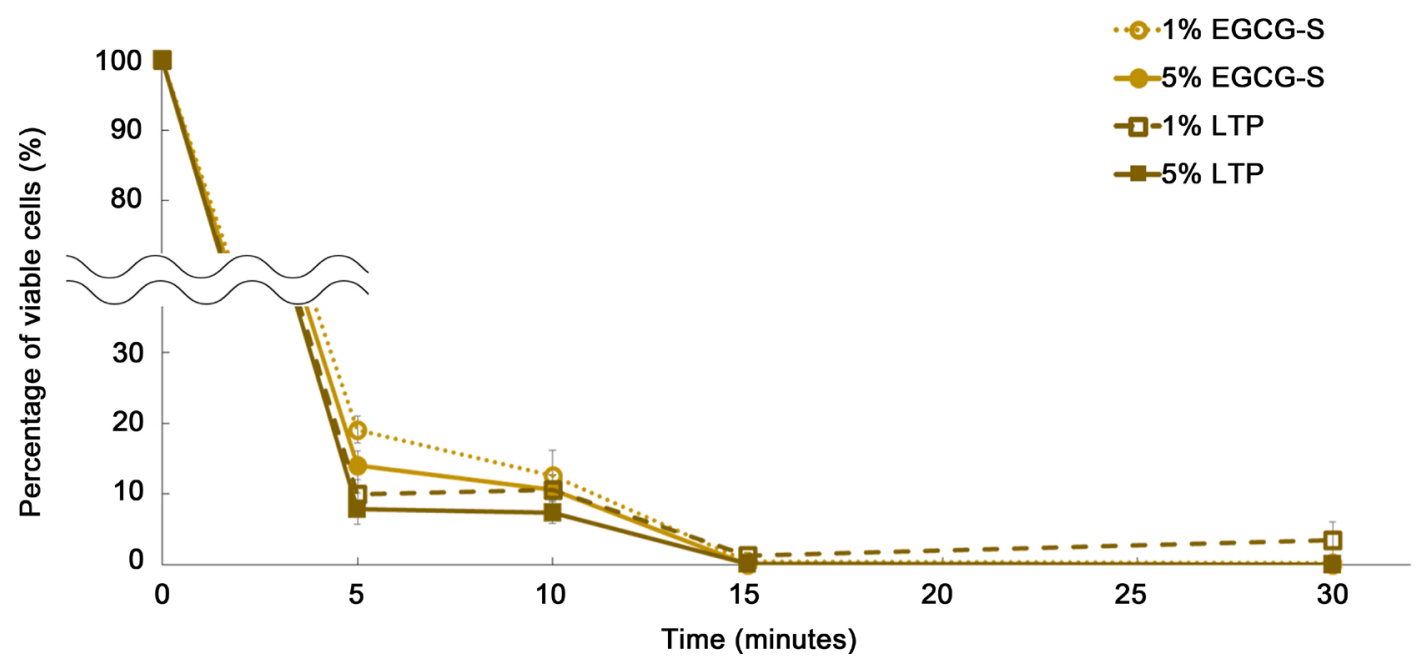

Figure 4. Time course study of lipid based green tea polyphenols on B. cereus endospore germination. No endospore germination was observed by the end of $15 \mathrm{~min}$.

percentage of inhibition ranging $85.98 \%-100 \%$. Similarly, LTP at $1 \%$ for 5 to 30 min, an average percentage of inhibition ranging $89.98 \%-98.67 \%$ while using $5 \%$ LTP for 5 to 30 min resulted in an average percentage of inhibition ranging $92.08 \%-100 \%$. A significant germination inhibition was shown when B. cereus endospores were treated for 5 min with EGCG-S or LTP while $15 \mathrm{~min}$ is needed for complete inhibition (100\%). It is clear that both EGCG-S and LTP demonstrated the comparable effects at $1 \%$ and $5 \%$ concentrations (Figure 4). These results concluded that a 15 -min treatment of 1\% EGCG-S or 1\% LTP is sufficient to completely inhibit the endospore germination of $B$. cereus.

\subsection{Microscopic Observation and Analysis}

\subsubsection{Transmission Electron Microscopy (TEM) Imaging Reveals the Structure Destructions in EGCG-S and EGCG Exposed Cells}

Transmission electron microscopy (TEM) was used to study the morphological and structural changes of spores with different tea polyphenols treatment. Control, 1\% EGCG or 1\% EGCG-S treated B. cereus endospores were viewed under TEM. The vegetative cells and endospores are shown in Figure 5. In the control samples, both vegetative cells and endospore forming cells are shown and endospore with coat, cortex and core were clearly illustrated. Images in Figure 6(A) revealed that EGCG was working in a mechanism that was leading to destruction of the spore coat of the endospore and agglutination of spores as reported [28]. Images in Figure 6(B) clearly demonstrated that the spore coats were completely destroyed in most of the endospores after treated with $1 \%$ EGCG-S. The results suggested that EGCG-S also uses a similar mechanism of EGCG by weakening the spore coat and destroying the structural integrity which leads to the inhibition of endospores germination.

\subsubsection{Scanning Electron Microscopy (SEM) Imaging Reveals the Surface Structure Changes in EGCG-S and EGCG Treated Cells}

SEM was used to study the surface of the endospores and Figure 7 showed that 
EGCG treated cells were agglutinated together and the morphology of the surface was also changed from smooth to rough and irregular shapes were also observed. For EGCG-S treated samples, the damage was more severe and some lysis was also observed. The SEM images further support the TEM results that the
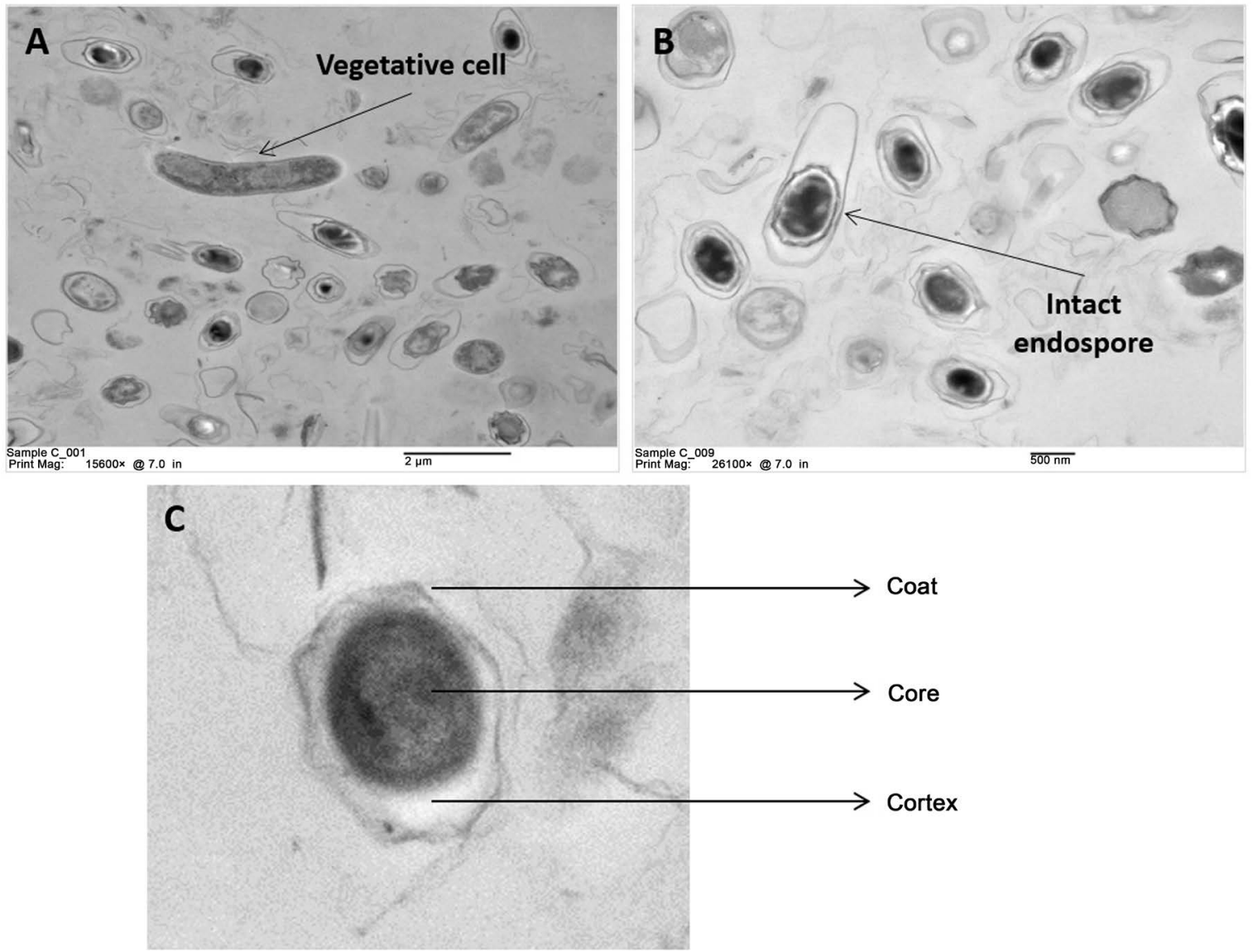

Figure 5. TEM of B. cereus untreated cells (control). (A) representative of vegetative cell. (B) representative of an intact endospore. (C) structure of a B. cereus spore.
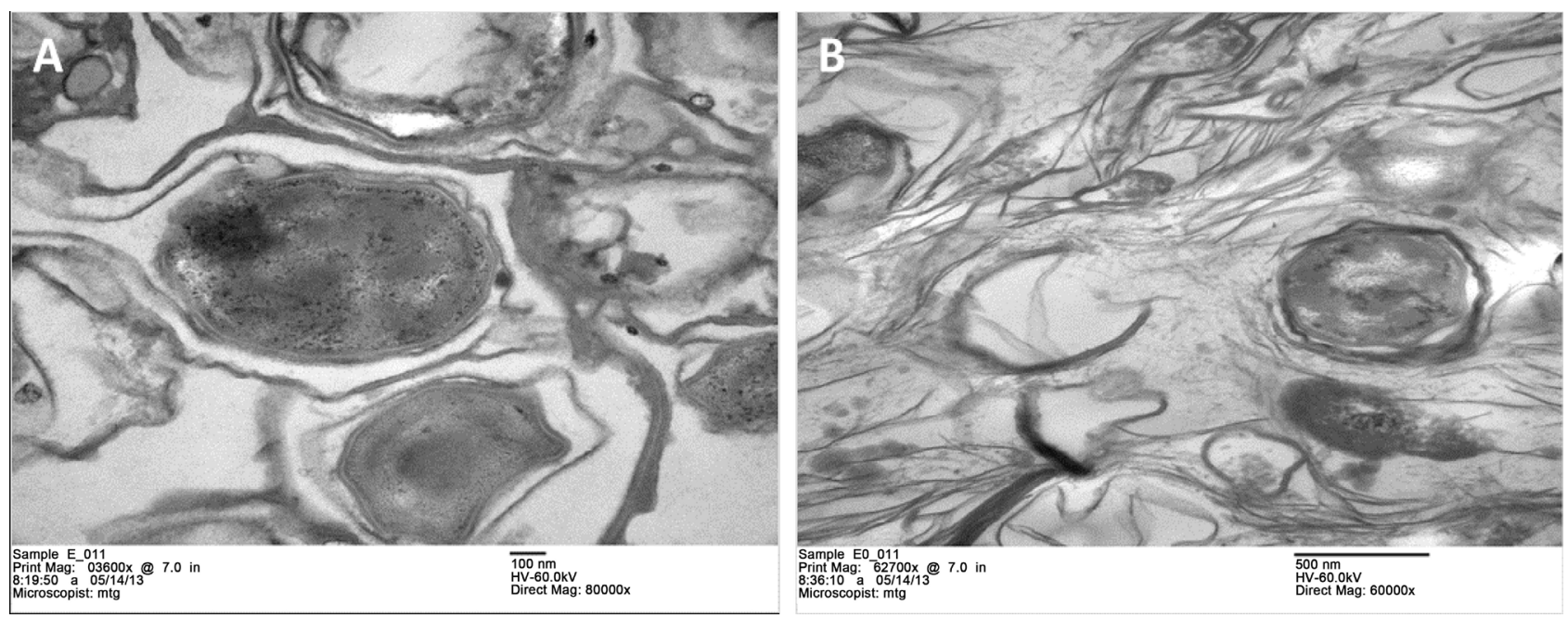

Figure 6. TEM of treated B. cereus endospores. (A) 1\% EGCG treated endospores showed the spore coat lost its structural integrity. (B) 1\% EGCG-S treated endospores showed completely morphological disruption. 

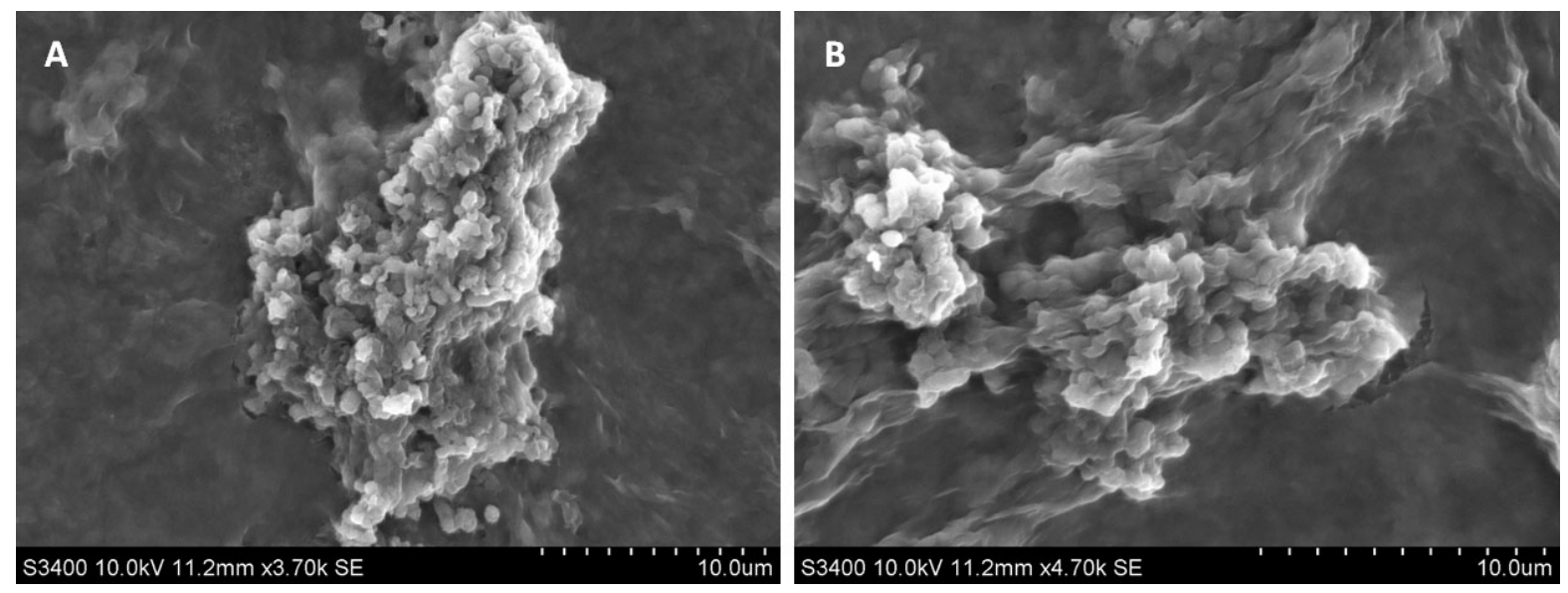

Figure 7. SEM of treated B. cereus endospores. (A) 1\% EGCG treated endospores showed agglutination and the morphology of the spore coat surface changed significantly. (B) 1\% EGCG-S treated endospores showed spore lysis.

tea polyphenols can destroy the integrity of the spores thus inhibit the germination of the endospore in spore forming bacteria.

\section{Discussion}

This study suggested that both EGCG-S and LTP have anti-spore activities against Bacillus spp. TEM and SEM studies indicated that the lipid based green tea polyphenols destroyed the surface of the spores of $B$. cereus which supports the finding by Hara-Kudo's group [28]. The concentrations (1\% and 5\%) used in this study displayed a very high percentage of inhibition. Future studies include using EGCG-S to treat other spore-forming bacteria (e.g. Clostridium spp.) should be carried out. Molecular research to elucidate the mechanisms of these tea polyphenols on spore germination should be carried out. Some genes such as $\cot E$ and $\cot A$ that code for spore outer coat [34] [35]; gerC and gerQ genes involved in germination [36] will be used to further understand the mechanisms of EGCG-S and LTP on the spores germination. Applications on food, medical devices and surface disinfection with these polyphenols should be investigated to elucidate their benefit for the food and medical industry.

\section{Conclusion}

EGCG-S and LTP have shown promising inhibitory effects of endospore germination. Ranges of inhibition were $94.92 \%-100 \%$ which is similar to EGCG and GTP treatment. We have also demonstrated promising inhibitory effects of $B$. cereus endospore germination by EGCG-S and LTP best at a $1 \%$ treatment concentration and at a 15-min minimal treatment time. This condition can inhibit the spore germination. EGCG-S and LTP are stable anti-spore agents may aid in preventing food and beverage spoilage caused by spore-forming bacteria as well as preventing contamination in the medical industry.

\section{Acknowledgements}

This work was supported by Montclair State University (MSU) Science Honors 
Innovation Program (SHIP) to BA and HT; MSU Faculty Scholarship Program (FSP) to LHL; NIH Grant 1R41 AI124738 to SDH; Seton Hall University (SHU) Biological Sciences Department Annual Research Fund and William and Doreen Wong Foundation to TC.

\section{References}

[1] Atrih, A. and Foster, S.J. (2002) Bacterial Endospores the Ultimate Survivors. International Dairy Journal, 12, 217-223. https://doi.org/10.1016/S0958-6946(01)00157-1

[2] Errington, J. (2003) Regulation of Endospore Formation in Bacillus subtilis. Nature Reviews Microbiology, 1, 117-126. https://doi.org/10.1038/nrmicro750

[3] Wells-Bennik, M.H., Eijlander, R.T., den Besten, H.M., Berendsen, E.M., Warda, A.K., Krawczyk, A.O., Nierop Groot, M.N., Xiao, Y., Zwietering, M.H., Kuipers, O.P. and Abee, T. (2016) Bacterial Spores in Food: Survival, Emergence, and Outgrowth. Annual Review of Food Science and Technology, 7, 457-482. https://doi.org/10.1146/annurev-food-041715-033144

[4] Andersson, A., Ronner, U. and Granum, P.E. (1995) What Problems Does the Food Industry Have with the Spore-Forming Pathogens Bacillus cereus and Clostridium perfringens? International Journal of Food Microbiology, 28, 145-155. https://doi.org/10.1016/0168-1605(95)00053-4

[5] Granum, P.E. and Lund, T. (1997) Bacillus cereus and Its Food Poisoning Toxins. FEMS Microbiology Letters, 157, 223-228. https://doi.org/10.1111/j.1574-6968.1997.tb12776.x

[6] Piggot, P.J. and Hilbert, D.W. (2004) Sporulation of Bacillus subtilis. Current Opinion in Microbiology, 7, 579-586. https://doi.org/10.1016/j.mib.2004.10.001

[7] Stephenson, K. and Hoch, J.A. (2002) Evolution of Signalling in the Sporulation Phosphorelay. Molecular Microbiology, 46, 297-304.

https://doi.org/10.1046/j.1365-2958.2002.03186.x

[8] Midura, T.F., Snowden, S., Wood, R.M. and Arnon, S.S. (1979) Isolation of Clostridium botulinum from Honey. Journal of Clinical Microbiology, 9, 282-283.

[9] Le Loir, Y., Baron, F. and Gautier, M. (2003) Staphylococcus aureus and Food Poisoning. Genetics and Molecular Research, 2, 63-76.

[10] Heyndrickx, M., Coorevits, A., Scheldeman, P., Lebbe, L., Schumann, P., Rodriguez-Diaz, M., Forsyth, G., Dinsdale, A., Heyrman, J., Logan, N.A. and De Vos, P. (2012) Emended Descriptions of Bacillus sporothermodurans and Bacillus oleronius with the Inclusion of Dairy Farm Isolates of Both Species. International Journal of Systematic and Evolutionary Microbiology, 62, 307-314. https://doi.org/10.1099/ijs.0.026740-0

[11] Russell, A.D. (1990) Bacterial Spores and Chemical Sporicidal Agents. Clinical Microbiology Reviews, 3, 99-119. https://doi.org/10.1128/CMR.3.2.99

[12] Sakanaka, S., Kim, M., Taniguchi, M. and Yamamoto, T. (1989) Antibacterial Substances in Japanese Green Tea Extract against Streptococcus mutans, a Cariogenic Bacterium. Agricultural and Biological Chemistry 53, 2307-2311.

[13] Shanrangi, A.B. (2009) Medicinal and Therapeutic Potentialities of Tea (Camellia sinensis L.)-A Review. Food Research International, 42, 529-535. https://doi.org/10.1016/j.foodres.2009.01.007

[14] Chu, T.-C., Adams, S.D. and Lee, L.H. (2014) Tea Polyphenolic Compounds against Herpes Simplex Viruses. In: Gupta, S.P. Ed., Cancer-Causing Viruses and Their In- 
hibitors, CRC Press, Taylor \& Francis Group, 321-344.

https://doi.org/10.1201/b16780-12

[15] De Oliveira, A., Adams, S.D., Lee, L.H., Murray, S.R., Hsu, S.D., Hammond, J.R., Dickinson, D., Chen, P. and Chu, T.C. (2013) Inhibition of Herpes Simplex Virus Type 1 with the Modified Green Tea Polyphenol Palmitoyl-Epigallocatechin Gallate. Food and Chemical Toxicology, 52, 207-215. https://doi.org/10.1016/j.fct.2012.11.006

[16] Fujimura, Y. (2015) Small Molecule-Sensing Strategy and Techniques for Understanding the Functionality of Green Tea. Bioscience, Biotechnology, and Biochemistry, 79, 687-699. https://doi.org/10.1080/09168451.2014.996205

[17] Imai, K., Suga, K. and Nakachi, K. (1997) Cancer-Preventive Effects of Drinking Green Tea among a Japanese Population. Preventive Medicine, 26, 769-775. https://doi.org/10.1006/pmed.1997.0242

[18] Isaacs, C.E., Wen, G.Y., Xu, W., Jia, J.H., Rohan, L., Corbo, C., Di Maggio, V., Jenkins, E.C. and Hillier, S. (2008) Epigallocatechin Gallate Inactivates Clinical Isolates of Herpes Simplex Virus. Antimicrobial Agents and Chemotherapy, 52, 962-970. https://doi.org/10.1128/AAC.00825-07

[19] Mukhtar, H. and Ahmad, N. (2000) Tea Polyphenols: Prevention of Cancer and Optimizing Health. American Journal of Clinical Nutrition, 71, 1698S-1702S.

[20] Steinmann, J., Buer, J., Pietschmann, T. and Steinmann, E. (2013) Anti-Infective Properties of Epigallocatechin-3-Gallate (EGCG), a Component of Green Tea. British Journal of Pharmacology, 168, 1059-1073. https://doi.org/10.1111/bph.12009

[21] Sueoka, N., Suganuma, M., Sueoka, E., Okabe, S., Matsuyama, S., Imai, K., Nakachi, K. and Fujiki, H. (2001) A New Function of Green Tea: Prevention of Lifestyle-Related Diseases. Annals of the New York Academy of Sciences, 928, 274-280. https://doi.org/10.1111/j.1749-6632.2001.tb05656.x

[22] Williamson, M.P., McCormick, T.G., Nance, C.L. and Shearer, W.T. (2006) Epigallocatechin Gallate, the Main Polyphenol in Green Tea, Binds to the T-Cell Receptor, CD4: Potential for HIV-1 Therapy. Journal of Allergy and Clinical Immunology, 118, 1369-1374. https://doi.org/10.1016/j.jaci.2006.08.016

[23] Zu, M., Yang, F., Zhou, W., Liu, A., Du, G. and Zheng, L. (2012) In Vitro Anti-Influenza Virus and Anti-Inflammatory Activities of Theaflavin Derivatives. Antiviral Research, 94, 217-224. https://doi.org/10.1016/j.antiviral.2012.04.001

[24] Haghjoo, B., Lee, L.H., Habiba, U., Tahir, H., Olabi, M. and Chu, T.-C. (2013) The Synergistic Effects of Green Tea Polyphenols and Antibiotics against Potential Pathogens. Advances in Bioscience and Biotechnology, 4, 959-967. https://doi.org/10.4236/abb.2013.411127

[25] Paterson, I. and Anderson, E.A. (2005) Chemistry. The Renaissance of Natural Products as Drug Candidates. Science, 310, 451-453. https://doi.org/10.1126/science.1116364

[26] Chen, P., Dickinson, D. and Hsu, S.D. (2009) Lipid-Soluble Green Tea Polyphenols: Stabilized for Effective Formulation. In: McKinley, H. and Jamieson, M. Eds., Handbook of Green Tea and Health Research, Nova Science Publishers, New York, 45-61.

[27] Chen, P., Tan, Y., Sun, D. and Zheng, X.M. (2003) A Novel Long-Chain Acyl-Derivative of Epigallocatechin-3-O-Gallate Prepared and Purified from Green Tea Polyphenols. Journal of Zhejiang University Science, 4, 714-718. https://doi.org/10.1631/jzus.2003.0714

[28] Hara-Kudo, Y., Yamasaki, A., Sasaki, M., Okubo, T., Minai, Y., Haga, M., Kondo, K. 
and Sugita-Konishi, Y. (2005) Antibacterial Action on Pathogenic Bacterial Spore by Green Tea Catechins. Journal of the Science of Food and Agriculture, 85, 23542361. https://doi.org/10.1002/jsfa.2259

[29] Sakanaka, S., Juneja, L.R. and Taniguchi, M. (2000) Antimicrobial Effects of Green Tea Polyphenols on Thermophilic Spore-Forming Bacteria. Journal of Bioscience and Bioengineering, 90, 81-85. https://doi.org/10.1016/S1389-1723(00)80038-9

[30] Wuytack, E.Y., Soons, J., Poschet, F. and Michiels, C.W. (2000) Comparative Study of Pressure- and Nutrient-Induced Germination of Bacillus subtilis Spores. Applied and Environmental Microbiology, 66, 257-261. https://doi.org/10.1128/AEM.66.1.257-261.2000

[31] Lee, L.H., Krumins, J.A. and Chu, T.C. (2015) Microbiology Laboratory Manuals. Hayden-McNeil, Plymouth.

[32] Chu, T.C., Murray, S.R., Hsu, S.F., Vega, Q. and Lee, L.H. (2011) Temperature-Induced Activation of Freshwater Cyanophage AS-1 Prophage. Acta Histochemica, 113, 294-299. https://doi.org/10.1016/j.acthis.2009.11.003

[33] Lee, L.A., Nguyen, Q.L., Wu, L., Horvath, G., Nelson, R.S. and Wang, Q. (2012) Mutant Plant Viruses with Cell Binding Motifs Provide Differential Adhesion Strengths and Morphologies. Biomacromolecules, 13, 422-431. https://doi.org/10.1021/bm2014558

[34] Costa, T., Serrano, M., Steil, L., Volker, U., Moran, C.P., Jr. and Henriques, A.O. (2007) The Timing of cotE Expression Affects Bacillus subtilis Spore Coat Morphology but Not Lysozyme Resistance. Journal of Bacteriology, 189, 2401-2410. https://doi.org/10.1128/JB.01353-06

[35] Su, J., Bao, P., Bai, T., Deng, L., Wu, H., Liu, F. and He, J. (2013) CotA, a Multicopper Oxidase from Bacillus pumilus WH4, Exhibits Manganese-Oxidase Activity. PLoS ONE, 8, e60573. https://doi.org/10.1371/journal.pone.0060573

[36] Ragkousi, K., Eichenberger, P., van Ooij, C. and Setlow, P. (2003) Identification of a New Gene Essential for Germination of Bacillus subtilis Spores with $\mathrm{Ca}^{2+}$-Dipicolinate. Journal of Bacteriology, 185, 2315-2329. https://doi.org/10.1128/JB.185.7.2315-2329.2003

\section{Submit or recommend next manuscript to SCIRP and we will provide best service for you:}

Accepting pre-submission inquiries through Email, Facebook, LinkedIn, Twitter, etc. A wide selection of journals (inclusive of 9 subjects, more than 200 journals) Providing 24-hour high-quality service User-friendly online submission system Fair and swift peer-review system Efficient typesetting and proofreading procedure Display of the result of downloads and visits, as well as the number of cited articles Maximum dissemination of your research work

Submit your manuscript at: http://papersubmission.scirp.org/

Or contact aim@scirp.org 